\title{
Issues in the Assessment of Effective Classroom Learning in Nigeria
}

\author{
Emaikwu, Sunday Oche PhD \\ (Associate Professor) College of Agricultural and Science Education Department of Educational Foundations \\ \& General Studies \\ Federal University of Agriculture PMB 2373 Makurdi, Benue State Nigeria
}

\begin{abstract}
There has been a progressive decline in the rate of achievement of students in schools in the recent times and this has led to a wide spread concern among considerable public about the methods used in the classroom learning. This article discusses some issues in the assessment of effective classroom learning in Nigeria. Specifically, the article explains the characteristics of effective learning and the tips for assessing classroom learning. The article submits that for any meaningful learning to take place, there ought to be an assessment during the course of instruction (formative assessment) so that students and teachers can receive feedback. It is affirmed that formative classroom assessment is not only the bond that holds teaching and learning together but it can motivate and shape learning as well as helps teachers to gauge student's mastery of required skills in addition to helping teachers determine whether students are prepared for testing that are often used for high-stake decisions. The article posits that what teachers assess, how they assess, and how teachers communicate their results send a clear message to students about what is worth learning, how it should be learned, and how well the teachers expect them to perform. The paper emphasizes that regular classroom assessment should be made an integral part of teaching, and that it should be used to inform and enhance the instruction and learning that goes on everyday in classrooms in Nigeria.
\end{abstract}

Keywords: Classroom, assessment, learning, formative assessment, education, Nigeria

\section{Introduction}

Education is expected to train the mind of its recipient for effective performance. It equips the individual with the information necessary for high level of human functioning. There has been progressive decline in the rate of performance of students in schools in the recent times. The public opinion about the appalling standard of performance of students graduating from schools in Nigeria in the recent time has reached an alarming crescendo. More disturbing is the common observation that many graduates in Nigeria are being rejected by the labor market because of low academic competence. Onah (2012) and Emaikwu (2012) affirmed that the fall in standard of achievement by students at all levels of education has been awfully reported and acknowledged by all and sundry in Nigeria. This fall in standard of performance at post primary level is incontrovertibly attributable to pedagogical approaches adopted by teachers in schools which invariably results in poor learning. It has been reported that learning and understanding of school subjects have been frustrated by the clumsy methods of instructional delivery in Nigeria (Etukudo, 2006). The resultant effect is the low achievement and low retention level in students' outcome in examinations.

In Nigeria, there is a wide spread concern among considerable public about the methods used in classroom learning. There exist some inherent inadequacies with the assessment techniques in schools. The demand for frequent testing in schools as stipulated by continuous assessment practice, the emphasis on cumulative test scores, in the face of gross inadequacies and ill-preparedness on the part of the teachers who implement the policy, leave much to be desired. The ways in which teacher-made tests, which form the bedrock of the present assessment practice in schools, are conducted poses threat to the maintenance of standards in educational system. The lack of standardization and inaccurate interpretation of test results are some of the evaluation problems, which teachers in schools have to contend with. Most of our schools still operate the traditional assessment practices of the last century. This involves assessing students with the sole aim of preparing them for examinations. The emphasis is placed on obtaining high marks without regard for understanding or the acquisition of the ability to apply the concepts learnt in solving real-life problems. For these reasons, an over-bearing emphasis is being placed on paper-and-pencil assessments. Even then the dominant practice is to concentrate on assessing the ability of the students to reproduce "facts or steps" in solving problems. Very little attention is given to the "higher mental task thinking and applications". This leads to decline in the ability to apply the knowledge in real-world; to analyze the information; to synthesize new information based on what was learnt; and to evaluate the outcome of knowledge applied. In the nutshell, assessment in Nigeria is mainly carried out after teaching has been completed (i.e., the assessment is 
summative). Ordinarily for any meaningful learning to take place, there ought to be an assessment during the course of instruction (i.e., formative assessment) so that students and teachers can receive feedback. This article therefore discusses issues in the assessment of effective classroom learning in Nigeria.

\section{The Concept of Learning and how it Occurs in an Organism}

An individual starts learning as soon as he is born and he continues learning throughout his life. Learning entails the acquisition of habits, knowledge, attitudes and skills. It is the act of acquiring new or modifying and reinforcing existing knowledge, behaviors, skills, values, or preferences and may involve synthesizing different types of information. The term 'learning' refers to a process resulting in some modification, relatively permanent, of the ways of thinking, feeling, and doing of the learner. Learning is considered to be unitary to the extent that the learner responds as a 'whole person' in a unified way to the whole situation. The teacher responds intellectually, emotionally, physically and spiritually at the same time. It involves new ways of doing things and attempts to adjust to new situations. It shows progressive change in behavior as the individual reacts to a situation. Learning is expected to bring about more or less permanent change in the learner's behavior. This change may range from the acquisition of a relatively simple skill, item of information to the mastery of complicated mechanical performance and application of difficult and abstract reading material. It however does not include physiological changes like fatigue, temporary sensory resistance and hunger. Progress over time tends to follow learning curves. Learning is not compulsory; it is contextual and it does not happen all at once, but builds upon and is shaped by what we already know. To that end, learning may be viewed as a process, rather than a collection of factual and procedural knowledge. Learning produces changes in the organism and the changes produced are relatively permanent.

Human learning may occur as part of education, personal development, schooling, or training. It may be goal-oriented and may be aided by motivation. The study of how learning occurs is part of educational psychology, neuropsychology, learning theory, and pedagogy. Learning may occur as a result of habituation or classical conditioning, seen in many animal species, or as a result of more complex activities such as play, seen only in relatively intelligent animals. There is evidence for human behavioral learning prenatally, in which habituation has been observed as early as 32 weeks into gestation, indicating that the central nervous system is sufficiently developed and primed for learning and memory to occur very early in development (Thomas \& Patrick, 2012).

\section{Characteristics of Effective Learning}

Yoakman and Simpson in Prakash (2011) enumerated some important characteristics of learning which are discussed as below:

Learning is growth: The individual grows as he lives. This growth implies both physical as well as mental development of the learner. The individual gains experiences through various activities and they are all sources of learning. The individual grows through living and learning. Thus growth and learning are inter-related and even synonymous.

Learning is adjustment: Learning enables the individual to adjust himself properly with the new situations. The individual faces new problems and new situations throughout his life and learning helps him to solve the problems encountered by him. That is why; many psychologists describe learning as "a process of progressive adjustment to the ever changing conditions which one encounters." The society in which we live is so complex and so dynamic that any one type of adjustment will not be suitable for all or many situations and problems. It is through learning that one could achieve the ability to adjust adequately to all situations of life.

Learning is purposeful: All kinds of learning are goal-oriented. The individual acts with some purpose. He learns through activities. He gets himself interested when he is aware of his objectives to be realized through these activities. Therefore all learning is purposive in nature.

Learning is experiential in nature: The individual learns through experiences. Human life is full of experiences. All these experiences provide new knowledge, understanding, skills and attitudes. Learning is not mere acquisition of the knowledge, skills and attitudes. It is also the reorganization of experiences or the synthesis of the old experiences with the new ones.

Learning is intelligent: Mere cramming without proper understanding does not make learning. Thus meaningless efforts do not produce permanent results. Any work done mechanically cannot yield satisfactory learning outcomes.

Learning is active: Learning is given more importance than teaching. It implies self-activity of the learning. Without adequate motivation the learner cannot work whole-heartedly and motivation is therefore at the root of self-activity. Learning by doing is thus an important principle of education, and the basis of all progressive methods of education.

Learning is both individual and social: Although learning is an individual activity, it is social also. Individual mind is consciously or unconsciously affected by the group activities. Individual is influenced by his peers, 
friends, relatives' parents and classmates and learns their ideas, feelings and attitudes in some way or others. The social agencies like family, church, markets, and clubs exert immense influence on the individual minds. As such, learning becomes both individual as well as social.

Learning is-the product of the environment: The individual lives in interaction of the society. Particularly, environment plays an important part in the growth and development of the individual. The physical, social, intellectual and emotional development of the child is molded and remolded by the objects and individuals in his environment. Therefore it is emphasized that child's environment should be made free from unhealthy and vicious matters to make it more effective for learning.

Learning affects the conduct of the learner: Learning is called the modification of behavior. It affects the learner's behavior and conduct. Every learning experience brings about changes in the mental structure of the learner. Therefore attempts should be made to provide such learning experiences which can mould the desired conduct and habits in the learners.

\section{The Concept of Assessment and the Rationale for Classroom Assessment}

Assessment is seen as data-gathering strategies, analyses, and reporting processes that provide information that can be used to determine whether or not intended outcomes are being achieved. Ugodulunwa and Ugwuanyi (1999) defined assessment as a process of measuring behaviours and using the result obtained in taking relevant decisions about a programme. Assessment therefore involves the collection of information about a child's knowledge, skills and attitudes as well as judgment, interpretation and actions taken. Assessment in education can be thought of as occurring whenever one person, in some kinds of interaction, directly or indirectly, with another, is conscious of obtaining and interpreting information about the knowledge and understanding or abilities and attitudes of another person. Assessment refers to the global process of synthesizing information about individuals so as to describe, understand and perhaps help them better. Assessment is a process, and it involves a collection of meaningful information to understand and help people cope with problems. In the process of assessment, tests are frequently used, but a variety of sources of information, both formal and informal, may be used. It is however not restricted to formal measurement procedures, but may also encompass other modes of obtaining information about individuals. Assessment therefore is the process of measuring behaviours and using the results of these measurements in taking relevant decisions about students, curriculum and instruction as well as educational policy.

Assessment in educational setting is a multifaceted process that involves more than the administration of a test. It is an evaluative and interpretative appraisal of performance which provides information that enables the teachers and the school personnel to make decision regarding the children they serve (Salvia, 2008). Different domains of behaviours are assessed in education and they include cognitive, affective and psychomotor domains.

Classroom assessment is the process of gathering evidence of what a student knows, understands, and is able to do. Classroom assessment plays an important role in students' achievement. It can help to identify students' learning needs. Teachers set specific criteria based on learning outcomes and expected levels of performance to evaluate students' learning. These criteria form the basis for evaluating and reporting student's progress. Teachers use their insight, knowledge about learning, and experience with students, along with the specific criteria they establish, to make judgments about students' performance in relation to prescribed learning outcomes for each subject or course and grade.

Classroom teachers can learn much about how students learn and how they respond to some particular teaching approaches through close observation of students in the process of learning, through the collection of frequent feedback on students' learning, through the design and use of modest classroom experiments. Classroom assessment can help individual instructors to obtain useful feedback on what, how much, and how well their students are learning. Teachers can use the information collected through assessment to refocus their teaching so as to assist students in making their learning more efficient and more effective. Classroom assessments can do more than just measuring learning. What we assess, how we assess, and how we communicate the results send a clear message to students about what is worth learning, how it should be learned, and how well we expect them to perform.

Classroom assessment is among the instructor's most essential educational tools. When properly developed and interpreted, assessments can help teachers to better understand what their students are learning. By providing the means to gather evidence about what students know and can do, classroom assessment can help teachers to identify students' strengths and weaknesses, monitor student learning progress as well as plan and conduct instruction effectively.

Ongoing informal and formal classroom assessment is the bond that holds teaching and learning together. Moreover, it allows educators to monitor teaching effectiveness and student learning as this can motivate and shape learning and instruction, It can help teachers gauge student's mastery of required skills in 
addition to helping teachers determine whether students are prepared for tests that are used for high-stakes decisions. Classroom assessment can help students to improve their own performances

\section{Characteristics of Effective Classroom Assessment}

Recall that classroom assessment is an approach designed to help teachers find out what students are learning in the classroom and how well they are learning it. Classroom assessment is characterized by many factors and they include the following approaches:

Learner-Centered: Classroom assessment focuses the attention of teachers and students on observing and improving learning, rather than on observing and improving teaching.

Teacher-Directed: No one can provide teachers with rules that will tell them what to do from moment to moment in the dynamic learning environment of a classroom. Classroom assessment respects the autonomy, academic freedom, and professional judgment of teachers.

Mutually Beneficial: For the fact that effective classroom assessment is focused on learning, classroom assessment requires the active participation of students. By cooperating in assessment, students reinforce their grasp of the course content and therefore strengthen their own evaluation skills.

Context-Specific: To be most useful, classroom assessments have to respond to the particular needs and characteristics of the teachers, students, and disciplines to which they are applied. Each class has its own particular dynamic, its own collective personality, and its own "chemistry." This is true even for different sections of the same course.

Ongoing: Classroom assessment is an ongoing process, perhaps best thought of as the creation and maintenance of a classroom "feedback." By employing a number of simple classroom assessment techniques that are quick and easy to use, teachers get feedback from students on their learning. Teachers are expected to collect some feedback on their students' learning and use that feedback in their teaching. Classroom assessment is an attempt to build on existing good practice by making it more systematic, more flexible, and more effective. Formative in nature: Classroom assessment is a formative rather than a summative approach to assessment. Its purpose is to improve the quality of student's learning, and not just to provide evidence for evaluating or grading students. Its aim is to provide teachers with information on what, how much, and how well students are learning, in order to help them to better prepare to succeed - both on the subsequent graded evaluations and in the world beyond the classroom. For classroom assessment to be meaningful, beneficial and efficient, it must be based on formative assessment rather than summative assessment

Formative assessment is usually undertaken during the process of the course of study. The feedback information that is received from such assessment is used to determine the type of changes needed before completion of the course in order to achieve the desired objectives. In other words, formative assessment refers to the assessment of the learning progress of the students during instructions. It is conducted to monitor the instructional process to determine whether learning is taking place as hitherto planned. The major function of formative assessment in the classroom is to provide continued feedback to both the teacher and the students about how things are going on in the teaching-learning situation. In this type of assessment, information is obtained through teacher's classroom oral questioning, homework and quizzes. The purpose of this type of assessment is to improve student's learning through provision of constructive feedback and remedial instruction (Ugodulunwa \& Ugwuanyi, 1999). It may also inhibit the rate of progress of students if the feedback is consistently negative and builds confidence in the students if the feedback from assessment is consistently positive.

Formative assessment according to Emaikwu (2013) performs the following functions:

a) It helps the student in learning the subject matter and behaviours for each unit of study.

b) Student learning can be properly paced at a suitable rate.

c) It promotes learning because it breaks the learning sequence into smaller units.

d) It helps the student to know how much of the required concept he has mastered and how much he is yet to master.

e) It builds confidence in the student if the feed-back from the assessment is consistently positive.

f) It may also inhibit the rate of progress of the student if the feed-back is consistently negative.

g) It reveals the particular point of difficulty; the particular ideas, skills, and process the student needs to work on.

Too much emphasis on the outcome of final examination leads teachers to concentrate on trying to cover the syllabus, without regard to whether the students understand what is taught or not. This kind of teaching has resulted in the students finishing even primary schools without the ability to read, write, do arithmetic and acquire the basic life skills. If teachers do not focus on formative assessment, this may have 
effect on learning as the teacher may not easily be able to correct the mistakes that students make in the classroom. For this reason, students may form many wrong concepts which are not detected in time. Since students are not given prompt feedback on the progress they are making in learning, they will not be able to plan for their learning and this could lead to lack of motivation to learn. Prompt feedbacks on learning help to keep the students' interests in learning.

\section{Tips for Planning Good Classroom Assessments}

In planning good classroom assessment the following vital points should be borne in mind by the classroom teachers in Nigeria.

Before developing a task, teacher should determine what skills and/or knowledge need to be assessed. The teacher should have the purpose or objective of the test clearly in mind. Instructional objectives are those behavioural changes which the teacher expects to notice in his students after they have been exposed to a particular topic. Instructional objectives are important because they are those things the examiners are testing for in the examinees. The domain of each objective, skill, etc, should be properly identified and specified. All the different levels of intellectual functioning such as knowledge, comprehension, application, analysis, synthesis and evaluation should be included.

If the purpose of the assessment is to determine how well students have mastered a particular unit of study, the teacher in Nigeria should make sure that the test parallels the work covered in class. If the major purpose of the test is to rank a selected group of students in order of their achievement, the questions should cover critical points of learning. The questions should challenge students to do more than memorize and recall facts.

The teacher should determine what type of assessment that would be most appropriate for the situation based on the nature of what he is teaching, the purpose of the instruction, and what he wants to measure in his students. If the assessment is a selected-response or fill-in-the-blank test that will be used to diagnose basic skills, it should contain some reasonable number of questions and preferably more - for each skill area. The questions pertaining to each skill area should be considered a subtest, and those subtests should yield separate scores.

During the construction of test items, the teacher is expected to check to see that directions for answering the test items are clear and accurate. The teacher should ensure that questions or tasks represent the topics or skills emphasized during instruction and that knowledge or skills that were not covered in class are not being unintentionally evaluated. It is expedient that the type of assessment used by the teacher is compatible with the method of instruction used in the classroom and the skill being measured. It is necessary that the assessment will contribute to the instructor's understanding of what the students know and can do.

The teacher should in Nigeria focus on assessing the most important and meaningful information rather than small, irrelevant facts. For example, after students read a passage about nutrition, rather than asking a comprehension question such as:

"How many vitamins are essential for humans? A. 7; B. 13; C. 15; D. 23," Consider asking: "Name at least seven vitamins that are essential for humans and explain why they are essential."

The teacher should prepare a table of specification for the test items he intends to set. The table of specification shows the course content and the relative emphasis placed on them. The purpose of table of specification is to define as clearly as possible the scope and emphasis of the test, to relate the objectives to the course contents, and to construct a balanced test. The table of specification may prevent the examiner from testing only the taxonomical levels where it is easy to develop test items. In determining how detailed the content area should be is to have a sufficient number of subdivisions to ensure adequate and detailed coverage. Without a well-thought and adequately prepared table of specification, there is a great possibility that the test, when finally constructed, will lack content validity. A test without a table of specification is like a building without a plan. The use of test blue print or table of specification according to Emaikwu (2013) will help to ensure that only those objectives actually involved in the instructional process will be assessed and that each objective will receive a proportional emphasis on the task in relation to the emphasis placed on the objectives by the examiners. The use of test blue print will ensure that no important objectives or areas will be advertently omitted by the examiners; in a long run, it also aids in the preparation of test items, in the production of valid and well balanced test items, in the clarification of objectives to both the teachers and the students, and in assisting the teacher to select the most appropriate teaching strategy.

To be valid, classroom assessments need to be fair to the examinees. Assessments should give all students an equal chance to show what they know and can do. In addition, assessments should only measure knowledge and skills related to their objectives. The teacher should help the students to understand what is expected of them, Research has shown that helping students understand what is expected of them, gives students an opportunity to become active participants in their own education. It also helps them to take responsibility for their own learning and judge the quality of their work. 
Before testing the students, the teacher is expected to develop scoring guidelines for performance assessments that define what constitutes an acceptable response and establish clearly defined levels of performance. He is also expected to discuss the guidelines with his students to ensure that they understand the kind of work expected at each performance level.

After the test the teacher should conduct a post-test discussion with his students. This will give him the opportunity to correct misconceptions and discuss issues raised by the assessment. The teacher should also discuss the different ways students responded to the task, and the strengths and weaknesses of each approach. The teacher is expected to be generous with feedback. A score alone doesn't give students sufficient information about their performance on the assessment. It behooves on the teacher to tell students their areas of strength and weakness, what they did correctly and incorrectly, what they can do differently next time to improve their performance

The teacher should keep the time limits in mind when conducting a classroom assessment. A test should be designed so that students can complete it in the time available. The amount of time given for an assessment is significant and affects test results. A test that has more questions than most students can complete in the allotted time measures knowledge and ability to perform rapidly and under time pressure. Results from such an assessment are difficult to interpret. It is impossible to tell whether students who performed poorly did so because they did not master the knowledge or skill being tested, or because they were unable to demonstrate their ability in the allotted time. When a test cannot be completed in the time available, questions at the end will probably be left unanswered - not because the students didn't know the answers or couldn't perform the task, but because they did not have enough time to address the questions. In addition, the teacher should make sure that the assessment can be completed in the allotted time. Above all the teacher should make sure that the assessment is fair and that all instances of offensive language, elitism, and bias have been eliminated. The teacher is expected to specify what decisions will be made with the information obtained from the assessment. Provision of feedback to examinees is highly essential. This feedback needs to be more than just a number. It needs to provide descriptive, constructive information that can help students to do better at a later time.

Before administering an assessment to measure what students have learned in class, it is useful for instructors to ask themselves: Based on what I have taught in class, can my students be expected to answer this? An assessment should also reflect real-world ways that knowledge and understanding are used. Assessments based on situations relevant to students' own experiences can motivate them to give their best performances.

The assessment process should not stop after the final paper has been scored. It is important for instructors to evaluate each assessment after it has been administered. Rather than assuming that all the questions in an assessment are completely valid or fair, the teacher should analyze the assessment to determine how good the items really are. When the teacher begins to analyze assessment results, the teacher should acknowledge that tests can have flaws. When assessments give unexpected results - for example, if the entire class does poorly on an assessment, or the students' responses are not consistent with the type of work the teacher was looking for - it is important to take a close look at the assessment to determine whether it is flawed in some way. Did all the students do poorly on the same question or set of questions? Did students who are more able, based on other evidence, do well on the assessment? Was the task well defined and clearly written? If the entire class failed the test, it might indicate that the material was not taught adequately, or the assessment was so poorly written that the students were unable to apply their knowledge appropriately.

The teacher should identify each student's strengths and weaknesses by taking a look at each student's strengths and weaknesses, based on his or her patterns of performance. This information can help the teacher to arrange for the next set of instructions to either remedy problems or build on strengths. For example, if a particular group of students has difficulty with one set of items that measures a similar set of skills then these students might need extra instruction or a different kind of instruction. If everybody in the class had difficulty with a particular issue that the teacher thought was emphasized in class, then he needs to determine if there was a problem with the instruction, the material or both.

Using many sources of evidence helps teachers to accurately interpret what each student really knows and can do. No single form of assessment works well in all situations and for all purposes. Each type of assessment has its own strengths and weaknesses. Each form of assessment provides a different type of evidence about what students know and can do. Taking advantage of more than one or two assessment methods increases the teacher's ability to fully understand the range of student's knowledge and skills. Some students will perform better on one type of assessment than another. In deciding which way to go, the teachers should use his professional judgment to weigh the benefits and drawbacks associated with each assessment strategy before deciding which one to use.

\section{Tips for Writing Better Selected-Response Assessments}

In Nigeria and in any part of the world, the teacher is expected to write clearly and simply by using vocabulary suitable for the students taking the assessment. Difficult language may overpower what the item was 
intended to assess. The teacher should avoid ambiguous or confusing words. It is a good idea to reread each item from the perspective of the students. The teacher is expected to keep questions short and specific as long and complicated questions slow students down and tend to test reading skill instead of content knowledge.

The teacher should not provide unintended clues to the correct answer. Clues can help students answer items correctly, even if the students have not mastered the content being tested. A stem clue occurs when an identical or similar term appears in both the stem and an option.

The teacher should avoid grammatical inconsistencies between the questions and answer choices. The teacher is expected to make all options grammatically consistent with the stem of the item. One of the most common examples of this problem occurs when an incomplete statement ending with "a" or "an" is followed by a set of answer choices in which only the correct answer completes the statement in a grammatically correct way. For example: The emblem on the signboard was a: A. angel B. elf C. ship D. owl. Incorrect answer choices should be clearly wrong but plausible. Students will quickly dismiss an incorrect answer choice that is obviously wrong. The teacher should try to use common misconceptions students have or common errors students make as possible choices. Answer choices should be as consistent in length, complexity, and grammatical construction as possible. If it is impossible to keep all the answer choices consistent, the teacher should try to have at least two of similar length and structure. For example, in a five-answer question, the teacher can provide two short answers and three long answers, or vice versa.

The teacher should avoid using the words always, never, all, and none in the answer choices. Students who have become familiar with tests may learn to recognize choices with these words as wrong answers. Questions should have only one correct answer. The teacher should avoid using all of the above or none of the above, particularly when the question calls for students to choose "the best answer." If "all of the above" is correct, then all of the options are correct, and the teacher has to count any answer the students mark as correct. Conversely, recognition of one wrong answer eliminates the "all of the above" answer, and recognition of one right answer eliminates the "none of the above" answer. This type of question can also hurt students who are very quick and know their subject matter. They may read the first answer choice, recognize it as correct, and mark it, then move on to the next question without reading the other answer choices.

The teacher should eliminate irrelevant sources of difficulty. If possible, use questions rather than incomplete sentences. Questions let students know right away what kind of information is being sought. Using the question format rather than the incomplete sentence format eliminates the possibility of inadvertently providing grammatical clues.

The teacher should avoid using negatives in the question. Negative wording can confuse students, who are accustomed to looking for true statements and may not notice the "not," making the question more difficult than intended. If there is a compelling reason for using a negatively worded stem in the question, the teacher should be sure to emphasize it by using a bold font, capping the word, or underlining it. The teacher should place answer choices in a logical, systematic order (e.g., chronological, ascending, descending, or alphabetical).

In true-false or alternative-response questions, the teacher should make sure that the question tests only one idea. The teacher is expected to state the item precisely so that it can be judged unequivocally true or false also he is to ask questions on important ideas rather than trivial. To reduce guessing, for false questions, the teacher should ask students to explain why the false answers are incorrect (Emaikwu, 2014).

\section{Conclusion}

Classroom learning in Nigeria and in any part of the globe is expected to be social, self-active, purposeful, creative and transferable. It can be concluded that each learner in the classroom is unique and has needs and problems not exactly like others. In every classroom, some learners have well developed intellectual abilities and others may be less able; some are skilled in self-expression, while others have difficulty; some are slow to learn, but others may be quick; some are sociable while others are shy and retiring. An effective teacher must consider the variations and differences among learners and provide information accordingly.

In learning situation, the teacher is expected to identify each student's strengths and weaknesses based on the patterns of performance. This information can help the teacher to arrange for the next set of instructions to either remedy problems or build on strengths.

Many teachers often concentrate on trying to cover the syllabus without regard to whether the students understand what is taught or not. This kind of approach has resulted in the students finishing even primary schools without the ability to read, write and acquire the basic life skills. If teachers do not focus on formative assessment, this may have effect on learning as the teacher may not easily be able to correct the mistakes that students make in the classroom. Prompt feedbacks on learning help to keep the students' interests in learning.

In conducting assessment, the teacher is expected to write clearly and simply by using vocabulary suitable for the students taking the test items. Since difficult language may overpower what the item is intended to assess, the teacher should avoid ambiguous or confusing words. It is a good idea for teachers to reread each item from the perspective of the students. 
Above all, what teachers assess, how they assess, and how they communicate the results send a clear message to students about what is worth learning, how it should be learned, and how well they expect students to perform in Nigeria.

\section{References}

[1]. Emaikwu, S. O. (2012). Assessment of the impact of students' mode of admission into university and their academic achievement in Nigeria. International Journal of Academic Research in Progressive Education and Development, 1 (3), 23-30.

[2]. Emaikwu, S.O. (2013). Fundamentals of test, measurement and evaluation with psychometric theories. Makurdi: Selfer Academic Press Ltd.

[3]. Emaikwu, S.O. (2014). Recent developments in the conduct of examination in Nigerian Universities: The clarion call for urgent utilization of objective test items. Indian Journal of Applied Research, 4 (7), 220-229.

[4]. Etukudo, U. E. (2006). The effect of computer assisted instruction on gender and performance of junior secondary school in mathematics. ABACUS Journal of Mathematical Association of Nigeria. 27 (1), 1-8

[5]. Onah, A. E. (2012). Effect of motivation on students' performance in mathematics. An undergraduate project submitted at the Federal University of Agriculture, Makurdi.

[6]. Prakash, J. (2011). The nine most important characteristics of learning by Yoakman and Simpson retrieved on 30 August, 2014 from http://preserveyourarticle.com

[7]. Salvia, J. (2008). Assessment in special and remedial education Bosten: Hougton Mifflin Company.

[8]. Schacter, J. (2013). Developmental psychology. Retrieved on 30 August, 2014 from http://en.wikipedia.org/wiki/Learning\#cite-1.

[9]. Thomas, A. A. \& Cross, K. P. (1993). Classroom assessment techniques: A handbook for college teachers. (2nd ed.). San Francisco: Jossey-Bass.

[10]. Ugodulunwa C. A. \& Ugwuanyi, C. L. (1999). Understanding educational evaluation. Jos: Fab Anieh (Nig.) Ltd. 